\title{
Depletion of Alveolar Macrophages Attenuates Hypoxic Pulmonary Hypertension but not Hypoxia-Induced Increase in Serum Concentration of MCP-1
}

\author{
M. ŽALOUDÍKOVÁ ${ }^{1}$, R. VYTÁŠEK ${ }^{1}$, O. VAJNEROVÁ ${ }^{2}$, O. HNILIČKOVÁ ${ }^{2}$, M. VÍZEK $^{1}$, \\ V. HAMPL ${ }^{2}$, J. HERGET ${ }^{2}$
}

${ }^{1}$ Department of Pathophysiology and ${ }^{2}$ Department of Physiology, 2nd Faculty of Medicine, Charles University in Prague, Czech Republic

Received September 11, 2015

Accepted March 18, 2016

On-line July 15, 2016

\begin{abstract}
Summary
Exposure to hypoxia, leading to hypoxic pulmonary hypertension $(\mathrm{HPH})$, is associated with activation of alveolar macrophages (AM). However, it remains unclear how AM participate in this process. There are studies which imply that the AM product monocyte chemoattractant protein-1 (MCP-1) plays an important role. Thus we tested: 1 . if the selective elimination of $A M$ attenuates $\mathrm{HPH}$ in rats, 2 . the correlation of MCP-1 plasmatic concentrations with the presence and absence of AM during exposure to hypoxia, 3 . the direct influence of hypoxia on MCP-1 production in isolated AM. We found that experimental depletion of AM attenuated the chronic hypoxia-induced increase in mean pulmonary arterial pressure, but did not affect the serum MCP-1 concentrations. Furthermore, the MCP-1 production by AM in vitro was unaffected by hypoxia. Thus we conclude that AM play a significant role in the mechanism of $\mathrm{HPH}$, but MCP-1 release from these cells is most likely not involved in this process. The increase of MCP-1 accompanying the development of $\mathrm{HPH}$ probably originates from other sources than AM.
\end{abstract}

\section{Key words}

Alveolar Macrophage - Monocyte Chemoattractant Protein-1 • Hypoxic Pulmonary Hypertension

\section{Corresponding author}

M. Žaloudíková, Department of Pathophysiology, Second Faculty of Medicine, Charles University, Plzeňská 130/221, 15006 Prague, Czech Republic. E-mail: marie.zaloudikova@lfmotol.cuni.cz

\section{Introduction}

Pulmonary hypertension is a condition that has been studied for decades because of its exacerbating effect on patients with chronic hypoxic diseases. Lung mast cells (MC) were implicated to participate in the development of hypoxic pulmonary hypertension (HPH) by several studies (Vajner et al. 2006, Mungall 1976), but not all (Zhu et al. 1983). In the systemic circulation, there is evidence that hypoxia can activate MC in vascular wall by circulating monocyte chemoattractant protein-1 (MCP-1) released from alveolar macrophages (Chao et al. 2009, Chao et al. 2011a). Because accumulation and activation of alveolar macrophages (AM) is characteristic of the development of hypoxic pulmonary hypertension (Frid et al. 2006, Hayashida et al. 2005, Madjdpour et al. 2003, Vergadi et al. 2011), we speculated that AM-derived MCP-1 could play a role in the activation of lung MC and thus in the mechanism of HPH. Therefore, we designed an experiment testing the role of AM and MCP-1 in HPH. We hypothesized that a selective elimination of AM by intrapulmonary application of clodronate-containing liposomes (Madjdpour et al. 2003) would result in decreased production of MCP-1 and attenuation of $\mathrm{HPH}$.

\section{Methods}

Study design

Combinations of intratracheal clodronate 
(AM-depleting agent) or vehicle administration with or without hypoxic exposure for 4, 10 or 15 days were used in adult male Wistar rats. For longer hypoxic exposures, the clodronate administrations were repeated every 5 days. The effectiveness of clodronate in reducing AM counts was assessed on day 4 of hypoxic exposure (4 days after clodronate administration). The effects of clodronate and/or hypoxia on serum MCP-1 levels were tested on day 4 and 10 of hypoxia. Finally, pulmonary hemodynamics and right heart ventricle weight were measured at the end of a 15-day hypoxic exposure. In a supplemental in vitro experiment, the ability of hypoxia ( 1 hour to 4 days) to stimulate MCP-1 production in the AM was tested.

All experimental procedures were performed in accordance with the European Community and NIH guidelines and approved by the Animal Studies Committee of the Second Medical School, Charles University, Prague.

\section{Clodronate administration}

Under brief ether anesthesia, a bolus $(350 \mu \mathrm{l})$ of a suspension of liposome-encapsulated clodronate (Encapsula NanoSciences LLC, clodronate disodium, $5 \mathrm{mg} / \mathrm{ml}$ ) in phosphate-buffered saline (PBS; $10 \mathrm{mM}$ $\mathrm{Na}_{2} \mathrm{HPO}_{4}, 10 \mathrm{mM} \mathrm{NaH} \mathrm{PO}_{4}, 140 \mathrm{mM} \mathrm{NaCl}$ at $\mathrm{pH} 7.4$ ) was injected intratracheally under visual control (Gonzalez et al. 2007). Control groups were given the same volume of phosphate-buffered saline or a suspension containing empty liposomes (without clodronate) or received no treatment. All rats recovered within $20 \mathrm{~min}$ after the intratracheal instillation. In animals exposed to hypoxia, this procedure was performed just before the initiation of the exposure and was repeated on days 5 and 10 of hypoxia (the latter only in the group exposed to hypoxia for 15 days).

\section{Hypoxic exposures}

The rats were either bred air, or exposed to hypoxia $\left(\mathrm{FiO}_{2} 0.1\right)$ for 4,10 or 15 days in a normobaric hypoxic chamber, as previously described (Hampl and Herget 1990).

The experimental groups are denoted with combinations of the letters $\mathrm{c}$ for clodronate, 1 for liposomes without clodronate, $\mathrm{s}$ for phosphate-buffered saline intratracheal instillation (without clodronate), $\mathrm{N}$ for normoxia and H4, H10 and H15 for 4, 10 and 15 days of hypoxic exposure, respectively (e.g. $15 \mathrm{H}-\mathrm{c}$ for clodronate-treated rats exposed to hypoxia for 15 days).

\section{Detection of AM depletion}

The effectiveness of clodronate-containing liposomes in depleting AM was estimated four days after liposome administration by visually counting AM in suspension obtained using bronchoalveolar lavage (BAL) stained by hematoxylin-eosin and trypan blue techniques. The BAL was carried out on animals euthanized by sodium thiopental overdose $(250 \mathrm{mg} / \mathrm{kg}$ i.p. $)$. The trachea was cannulated and saline $(10 \mathrm{ml})$ was instilled slowly into the lungs. The suspension was then removed and the washout was repeated 8 times. The BAL fluid was centrifuged for $10 \mathrm{~min}$ at $2500 \mathrm{rpm}$ and the cell pellets were pooled and resuspended in $1 \mathrm{ml}$ of saline. The total number of living cells in BAL was counted under a microscope using trypan blue staining dissolved in physiological salt solution. The number of macrophages in BAL was calculated from the percentage of AM in a smear fixed by ice-cold methanol and stained by hematoxylin eosin.

\section{MCP-1 measurement}

Serum concentrations of MCP-1 were detected by a standard sandwich ELISA kit from Invitrogen Corporation in serum obtained by centrifugation of blood acquired by syringe puncture of the descending aorta.

\section{Hemodynamic and morphologic measurements}

Mean pulmonary arterial blood pressure (MPAP, $\mathrm{mm} \mathrm{Hg}$ ) was recorded in rats anesthetized with sodium thiopental (50 mg/kg b.w. i.p.; ICN Czech Republic, Roztoky, Czech Republic) and spontaneously breathing room air. A polyethylene catheter was inserted in the pulmonary artery via the right jugular vein (Herget and Paleček 1972). A separate batch of identically treated rats was used to measure right ventricular weight. These rats were euthanized by an overdose of sodium thiopental ( $250 \mathrm{mg} / \mathrm{kg}$ i.p.) and the hearts were removed from the chest. The right heart ventricle (RV) and the left ventricle plus septum $(\mathrm{LV}+\mathrm{S})$ were separated, their wet weight was measured and the $\mathrm{RV} / \mathrm{LV}+\mathrm{S}$ ratio was calculated (Hampl and Herget 1990).

\section{Supplemental in vitro experiment}

The concentration of MCP-1 was measured in media of AM cultivated in normoxia or hypoxia $\left(10 \% \mathrm{O}_{2}\right)$ after $1,6,24$, and 96 hours, as well as in the lysate of AM after 4 days of normoxia or hypoxia. Additionally, MCP-1 concentration was assayed in the lysate of AM isolated immediately after a 4-day exposure 
of rats to hypoxia $\left(10 \% \mathrm{O}_{2}, \mathrm{n}=8\right)$ or living in normoxia $(n=6)$

The AM were obtained by BAL as described above, except that $5 \times 8 \mathrm{ml}$ of Hanks buffered salt solution was used for washout. The suspension of cells was centrifuged for $10 \mathrm{~min}$ at $1500 \mathrm{~g}$. The sediment was resuspended in $400 \mu \mathrm{l}$ of Dulbecco's Modified Eagle's Medium. Half of the samples were then incubated in hypoxia, half in normoxia, and MCP-1 was periodically measured in the media of all samples as described above. After 4 days of hypoxia, the cell suspensions were lysed by freezing, resuspended in $150 \mu \mathrm{l}$ of PBS and centrifuged at $20000 \mathrm{~g}$. The pellets were removed and supernatants were used to measure MCP-1. The total protein concentration in the samples was assayed using a BCA protein assay kit (Pierce No. 23225) and did not differ between the groups.

All chemicals and kits, unless stated otherwise, were from Sigma-Aldrich, Prague, Czech Republic.

The statistical analysis was performed by ANOVA with Tukey's multiple comparisons post hoc test; all results are expressed as mean \pm SEM. $\mathrm{P}<0.05$ was considered significant.

\section{Results}

\section{AM depletion}

As expected, the administration of clodronatecontaining liposomes reduced the AM count in BAL obtained from rats exposed to hypoxia for 4 days (Fig. 1).

Effect of AM depletion and hypoxia on the serum MCP-1 levels

Four days of exposure to hypoxia induced a rise in the serum level of MCP-1 (Fig. 2). However, in contrast to our hypothesis, this increase was unaffected by the AM depletion by clodronate. After ten days of hypoxia, the serum MCP-1 concentrations returned to the control level and, again, were not affected by the clodronate treatment (Fig. 2).

Effect of clodronate on the pulmonary artery blood pressure

MPAP was elevated in all rats exposed to 15 days of hypoxia (Fig. 3). This increase was significantly reduced (but not eliminated) in the hypoxic group repeatedly treated with clodronate-containing liposomes when compared with the hypoxic group treated with solvent only (Fig. 3).

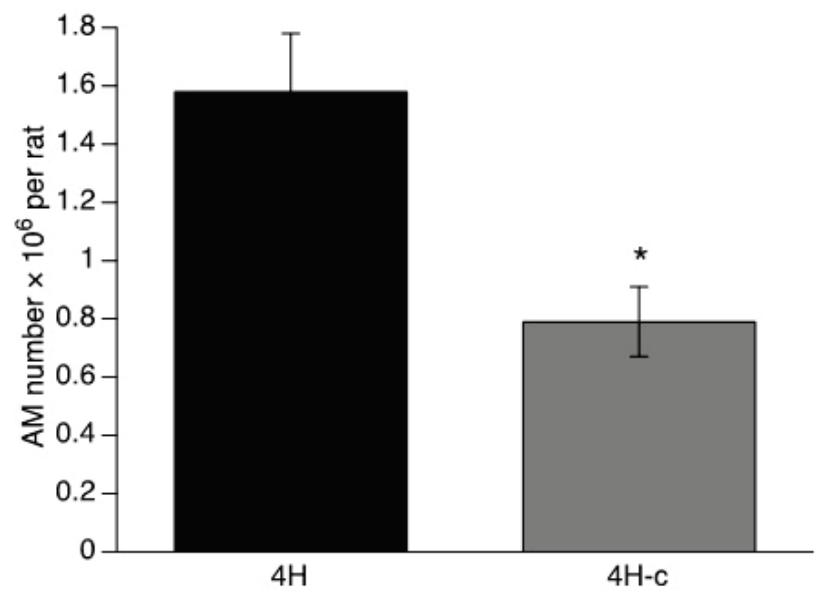

Fig. 1. Intratracheal instillation of clodronate-containing liposomes markedly reduces the number of alveolar macrophages in rats exposed to hypoxia for 4 days. $4 \mathrm{H}=$ rats exposed to $10 \%$ $\mathrm{O}_{2}$ for 4 days with no other treatment $(n=6), 4 \mathrm{H}-\mathrm{C}=$ rats exposed to $10 \% \mathrm{O}_{2}$ for 4 days treated intratracheally with clodronate-containing liposomes $(n=6)$. * $P=0.0085$.

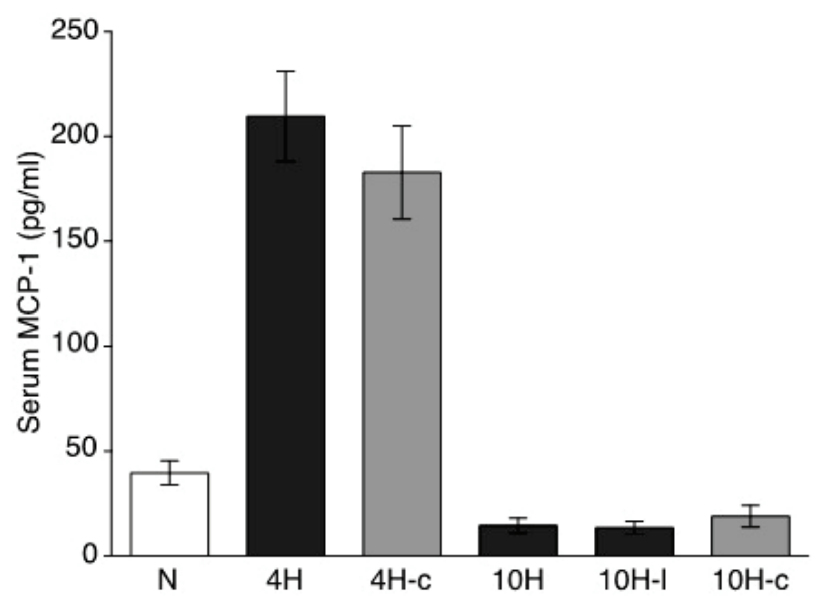

Fig. 2. Chronic hypoxia transiently elevates serum MCP-1 levels, and this effect is not affected by alveolar macrophages depletion by clodronate treatment. $\mathrm{N}=$ normoxic control rats $(\mathrm{n}=12), 4 \mathrm{H}=$ rats exposed to $10 \% \mathrm{O}_{2}$ for 4 days with no other treatment $(n=7), 4 \mathrm{H}-\mathrm{c}=$ rats exposed to $10 \% \mathrm{O}_{2}$ for 4 days treated intratracheally with clodronate-containing liposomes $(n=7), 10 \mathrm{H}$ = rats exposed to $10 \% \mathrm{O}_{2}$ for 10 days with no other treatment $(n=8), 10 \mathrm{H}-\mathrm{I}=$ rats exposed to $10 \% \mathrm{O}_{2}$ for 10 days treated with clodronate-free liposomes $(n=7), 10 \mathrm{H}-\mathrm{c}=$ rats exposed to $10 \% \quad \mathrm{O}_{2}$ for 10 days treated with clodronate-containing liposomes $(n=8)$. Only the $4 \mathrm{H}$ and $4 \mathrm{H}-\mathrm{c}$ groups differ from all other groups $(P<0.0001)$, but not from each other.

\section{Effect of clodronate on right ventricular hypertrophy}

Right ventricular hypertrophy, as assessed by significantly elevated $\mathrm{RV} / \mathrm{LV}+\mathrm{S}$ ratio, was induced by 15 days of hypoxia in rats treated with vehicle, but not in those treated with clodronate (Fig. 4). However, the difference in $\mathrm{RV} / \mathrm{LV}+\mathrm{S}$ between $4 \mathrm{H}-\mathrm{s}$ and $4 \mathrm{H}-\mathrm{c}$ did not reach statistical significance. 


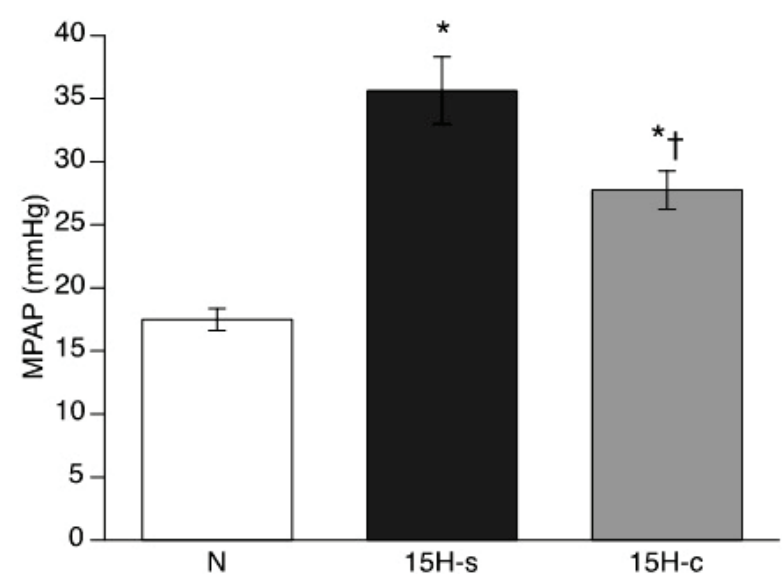

Fig. 3. Depletion of alveolar macrophages by clodronate reduces pulmonary hypertension induced by 15 days of hypoxia. MPAP = mean pulmonary arterial blood pressure, $\mathrm{N}=$ normoxic control rats $(n=4), 15 \mathrm{H}-\mathrm{s}=$ rats exposed to $10 \% \mathrm{O}_{2}$ for 15 days treated intratracheally with phosphate-buffered saline $(n=8), 15 \mathrm{H}-\mathrm{c}=$ rats exposed to $10 \% \mathrm{O}_{2}$ for 15 days treated with clodronatecontaining liposomes $(n=8) .{ }^{*} P<0.05$ vs. the $N$ group. ${ }^{\dagger} \mathrm{P} \leq 0.05$ vs. the $15 \mathrm{H}-\mathrm{s}$ group.

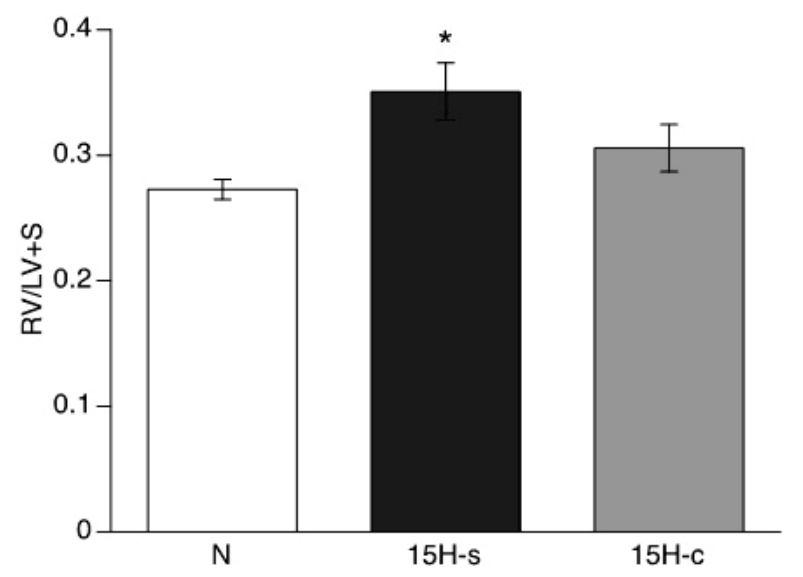

Fig. 4. Depletion of alveolar macrophages by clodronate prevents right ventricular hypertrophy during 15 days of hypoxia. $\mathrm{N}=$ normoxic control rats $(n=6), 15 \mathrm{H}-\mathrm{s}=$ rats exposed to $10 \% \mathrm{O}_{2}$ for 15 days treated intratracheally with phosphatebuffered saline $(n=6), 15 \mathrm{H}-\mathrm{c}=$ rats exposed to $10 \% \mathrm{O}_{2}$ for 15 days treated with clodronate-containing liposomes $(n=6)$. $* \mathrm{P}<0.05$ vs. the $\mathrm{N}$ group. All other differences are not significant.

\section{Effect of hypoxia on AM production of MCP-1 in vitro}

In vitro cultivation of $\mathrm{AM}$ resulted in an increase in MCP-1 concentration in media that reached a plateau after 24 hours. This pattern, however, was unaffected by cultivation under hypoxic conditions (Fig. 5). The content of MCP-1 in AM lysate after 4 days of hypoxic cultivation was under the detection limit of the ELISA method used $(\sim 15 \mathrm{pg} / \mathrm{ml})$, as was that of cells cultivated under normoxic conditions. The same was true for lysates of AM freshly obtained from rats at the end of their 4-day exposure to hypoxia and from normoxic control rats.

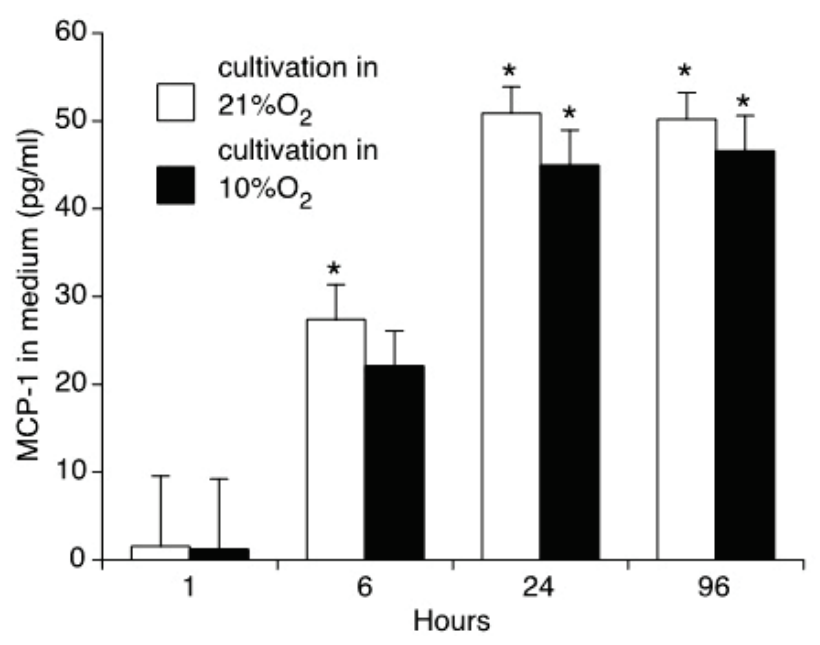

Fig. 5. MCP-1 accumulation in the media of cultured alveolar macrophages is unaffected by hypoxic conditions. The values at 1 hour after the onset of cultivation are below the detection limit $(\sim 15 \mathrm{pg} / \mathrm{ml})$. * $\mathrm{P}<0.05$ vs. relevant group at 1 hour. The differences between hypoxic and corresponding normoxic groups are not significant. $n=4$ per group, except for $t=1 h r$, where $n=8$ per group.

\section{Discussion}

This study was designed to explore the hypothesis that AM participate in the mechanism of $\mathrm{HPH}$ by activating $\mathrm{MC}$ through an increased production of MCP-1. In support of this hypothesis, we found that MCP-1 concentration in serum was elevated on the $4^{\text {th }}$ day of hypoxic exposure and returned to control level by the $10^{\text {th }}$ day of exposure. Furthermore, experimental depletion of AM by clodronate attenuated the chronic hypoxia-induced increases in MPAP and in the right heart ventricle relative weight. However, two findings contradict our hypothesis. First, AM depletion did not affect the serum MCP-1 concentrations in hypoxia. And second, MCP-1 production by $\mathrm{AM}$ in vitro was unaffected by hypoxia. Thus, the results taken together confirm that AM do have a significant role in the mechanism of HPH, but it is not mediated by MCP-1. Other sources than AM must participate in MCP-1 production in hypoxia, but regardless of its source, circulating MCP-1 does not participate in the mechanism of $\mathrm{HPH}$.

The mechanism/s underlying the development of hypoxic pulmonary hypertension is still far from being clear, even though an increasing number of studies imply the involvement of inflammation and monocytes/ macrophages. Interestingly, Chao et al. (2011) reported that hypoxia-induced systemic inflammation is mediated by mast cells activated by AM-derived MCP-1. The 
increase in plasmatic concentration of MCP after 4 days of hypoxia expanded on the results of Chao, who found a similar increase $60 \mathrm{~min}$ after hypoxic exposure. Surprisingly, AM depletion did not affect this increase. This fact can be explained by the duration of hypoxic exposure. Chao et al. (2011) found different concentrations of MCP between control and AM-depleted rats after $90 \mathrm{~min}$, it is therefore possible that prolonged hypoxia stimulated MCP production also in other cells. The production of MCP-1 by other cells than AM, including endothelial, fibroblasts, epithelial or smooth muscle, is well documented (Deshmane et al. 2009), however, information about the effects of hypoxia on this production are scarce and controversial (Bosco et al. 2004, Chao et al. 2011).

The reducing effect of AM depletion on MPAP corresponds well with reports showing that the development of HPH is preceded and/or accompanied by an inflammatory response involving AM (Minamino et al. 2001, Frid et al. 2006, Hayashida et al. 2005). More recently, Vergadi et al. (2011) demonstrated a link between M2 polarized AM and the promotion of HPH.

The finding that in vitro hypoxia did not affect MCP-1 production by isolated AM contrasted with the results of Chao et al. (2009), who reported an elevation of
MCP-1 production by hypoxia in comparable settings. On the other hand, Bosco et al. (2004) reported that hypoxia inhibits MCP-1 production in cell lines of mouse macrophages and T-lymphocytes.

Our results strongly refute the role of circulating MCP-1 in the HPH mechanism. The possibility that MCP-1 participates in inducing HPH has also been questioned recently by a report that mice with a CCR2 (MCP-1 receptor) deficiency displayed more severe HPH than those with CCR2 intact (Yu et al. 2013).

In conclusion, we have shown that AM participate significantly in the mechanism of HPH and in accordance with Hashimoto-Kataoka et al. 2015 they are supposed to be a potential target for treating of pulmonary hypertension. However their involvement is not mediated by MCP-1, despite the fact that the levels of circulating MCP-1 transiently increase in hypoxia (from other sources than AM).

\section{Conflict of Interest}

There is no conflict of interest.

\section{Acknowledgements}

This study was supported by IGA NT 13358-4.

\section{References}

BOSCO MC, PUPPO M, PASTORINO S, MI Z, MELILlO G, MASSAZZA S, RAPISARDA A, VARESIO L: Hypoxia selectively inhibits monocyte chemoattractant protein-1 production by macrophages. $J$ Immunol 172: 1681-1690, 2004.

CHAO J, WOOD JG, BLANCO VG, GONZALEZ NC: The systemic inflammation of alveolar hypoxia is initiated by alveolar macrophage-borne mediator(s). Am J Respir Cell Mol Biol 41: 573-582, 2009.

CHAO J, DONHAM P, VAN ROOIJEN N, WOOD JG, GONZALEZ NC: Monocyte chemoattractant protein-1 released from alveolar macrophages mediates the systemic inflammation of acute alveolar hypoxia. Am J Respir Cell Mol Biol 45: 53-61, 2011a.

CHAO J, WOOD JG, GONZALEZ NC: Alveolar macrophages initiate the systemic microvascular inflammatory response to alveolar hypoxia. Respir Physiol Neurobiol 178: 439-448, $2011 \mathrm{~b}$.

DESHMANE SL, KREMLEV S, AMINI S, SAWAYA BE: Monocyte chemoattractant protein-1 (MCP-1): an overview. J Interferon Cytokine Res 29: 313-326, 2009.

FRID MG, BRUNETTI JA, BURKE DL, CARPENTER TC, DAVIE NJ, REEVES JT, ROEDERSHEIMER MT, VAN ROOIJEN N, STENMARK KR: Hypoxia-induced pulmonary vascular remodeling requires recruitment of circulating mesenchymal precursors of a monocyte/macrophage lineage. Am J Pathol 168: 659-669, 2006.

GONZALEZ NC, ALLEN J, BLANCO VG, SCHMIDT EJ, VAN ROOIJEN N, WOOD JG: Alveolar macrophages are necessary for the systemic inflammation of acute alveolar hypoxia. J Appl Physiol 103: 1386-1394, 2007.

HAMPL V, HERGET J: Perinatal hypoxia increases hypoxic pulmonary vasoconstriction in adult rats recovering from chronic exposure to hypoxia. Am Rev Respir Dis 142: 619-624, 1990. 
HASHIMOTO-KATAOKA T, HOSEN N, SONOBE T, ARITA Y, YASUI T, MASAKI T, MINAMI M, INAGAKI T, MIYAGAWA S, SAWA Y, MURAKAMI M, KUMANOGOH A, YAMAUCHI-TAKIHARA K, OKUMURA M, KISHIMOTO T, ET AL.: Interleukin-6/interleukin-21 signaling axis is critical in the pathogenesis of pulmonary arterial hypertension. Proc Natl Acad Sci U S A 112: E2677-E2686, 2015.

HAYASHIDA K, FUJITA J, MIYAKE Y, KAWADA H, ANDO K, OGAWA S, FUKUDA K: Bone marrow-derived cells contribute to pulmonary vascular remodeling in hypoxia-induced pulmonary hypertension. Chest 127: 1793-1798, 2005.

HERGET J, PALEČEK F: Pulmonary arterial blood pressure in closed chest rats. Changes after catecholamines, histamine and serotonin. Arch Int Pharmacodyn Ther 198: 107-117, 1972.

MADJDPOUR C, JEWELL UR, KNELLER S, ZIEGLER U, SCHWENDENER R, BOOY C, KLÄUSLI L, PASCH T, SCHIMMER RC, BECK-SCHIMMER B: Decreased alveolar oxygen induces lung inflammation. Am J Physiol Lung Cell Mol Physiol 284: L360-L367, 2003.

MINAMINO T, CHRISTOU H, HSIEH CM, LIU Y, DHAWAN V, ABRAHAM NG, PERRELLA MA, MITSIALIS SA, KOUREMBANAS S: Targeted expression of heme oxygenase-1 prevents the pulmonary inflammatory and vascular responses to hypoxia. Proc Natl Acad Sci U S A 98: 8798-8803, 2001.

MUNGALL IPF: Hypoxia and lung mast cells: influence of disodium cromoglycate. Thorax 31: 94-100, 1976.

VAJNER L, VYTÁŠEK R, LACHMANOVÁ V, UHLÍK J, KONRÁDOVÁ V, NOVOTNÁ J, HAMPL V, HERGET J: Acute and chronic hypoxia as well as 7-day recovery from chronic hypoxia affects the distribution of pulmonary mast cells and their MMP-13 expression in rats. Int J Exp Pathol 87: 383-391, 2006.

VERGADI E, CHANG MS, LEE C, LIANG OD, LIU X, FERNANDEZ-GONZALEZ A, MITSIALIS SA, KOUREMBANAS S: Early macrophage recruitment and alternative activation are critical for the later development of hypoxia-induced pulmonary hypertension. Circulation 123: 1986-1995, 2011.

YU YR, MAO L, PIANTADOSI CA, GUNN MD: CCR2 deficiency, dysregulation of Notch signaling, and spontaneous pulmonary arterial hypertension. Am J Respir Cell Mol Biol 48: 647-654, 2013.

ZHU YJ, KRADIN R, BRANDSTETTER RD, STATON G, MOSS J, HALES CA: Hypoxic pulmonary hypertension in the mast cell-deficient mouse. $J$ Appl Physiol 54: 680-686, 1983. 